\title{
Morphological and molecular characterization of Gordionus alpestris (Nematomorpha) from the North-West Caucasus, Russia
}

\author{
S. E. SPIRIDONOV ${ }^{1}$, V. YU. SCHMATKO ${ }^{2}$
}

${ }^{1}$ Center of Parasitology, A.N. Severtsov Institute of Ecology and Evolution, Russian Academy of Sciences, Leninskii pr., 33, Moscow 119071, Russia, E-mail: s_e_spiridonov@rambler.ru; ${ }^{2}$ Department of Zoology, Faculty of Natural Sciences, Southern Federal University, B. Sadovaya, 105/45, Rostov-na-Donu, 344006, Russia

\begin{abstract}
Summary
During the survey of Pachyiulus krivolutskyi Golovatch, 1977 (Diplopoda) near Nickel' in Adygei Republic (Russia) in the summer 2009 the infestation of these millipeds with nematomorphs of the species Gordionus alpestris was revealed. The morphology of naturally emerging nematomorphs was studied in SEM. The partial sequences of $18 \mathrm{~S}$ (883 bp) and 28S (393 bp) rDNA PCR-products were obtained and analyzed. An unexpectedly high level of differences between Gordionus alpestris found in diplopods of North-West Caucasus and other molecularly studied representatives of the family Chordodidae was observed.
\end{abstract}

Keywords: diplopod host; Gordionus; nematomorphs; Pachyiulus; rDNA

\section{Introduction}

Horsehair worms (Nematomorpha: Gordiida) are obligate parasites of invertebrates, mainly insects. The fauna of these worms in temperate areas is quite rich and represented by about a dozen genera. For some of these genera characteristic groups of hosts can be defined. The nematomorphs of the genera Parachordodes, Gordionus and $\mathrm{Pa}$ ragordionus are usually reported from terrestrial beetles (mainly Carabidae and Tenebrionidae), but occasionally, some exclusions from this host circle are also recorded. The survey of diplopod populations along the streams near Nickel' in Adygei Republic (Russia) performed in the summer 2009 revealed infestation of these millipedes with nematomorphs. Results of morphological examination of these parasitic worms in SEM and sequence analysis of two domains of ribosomal DNA are presented below.

\section{Material and methods}

Diplopods and naturally emerging nematomorphs were collected in the natural habitats around Nickel' and trans- ported to the laboratory in Rostov-na-Donu. Emerging nematomorphs and their diplopod hosts were fixed in $70 \%$ ethanol.

The length (L) and body weight (W) of nematomorphs were measured on the specimens soaked with water for 30 minutes and superficially dried with filter paper. Mid-body diameter (MBD) was measured under a dissecting microscope on specimens in water. The terminology for morphological features of nematomorphs was used according to Schmidt-Rhaesa (2002). The measurements are presented in the text as the value for the voucher specimen and values for additional specimens (in parentheses). Permanent slides of the male posterior end and the cuticle were prepared as described in Spiridonov et al. (1992). The fragments of about $0.5-1 \mathrm{~mm}$ length were excised from the middle part of female body and from the middle and posterior parts (sectioned anterior of the cloacal opening) of males for SEM examination. Specimens were dehydrated in an increasing (up to $96 \%$ ) ethanol series and three changes of acetone, critically point dried, coated with gold and examined in CamScan and Jeol microscopes.

Total genomic DNA was extracted from the same specimens (male and female) of nematomorphs from which the body parts were used for the SEM study. The body was cut into smaller $(2-4 \mathrm{~mm})$ pieces and DNA was extracted with Wizard $\AA^{\circledR}$ Genomic DNA Purification Kit. Partial sequences of $18 \mathrm{~S}$ and $28 \mathrm{~S}$ rDNA were obtained with the use of primer pairs 18SF1 - CAT GCA TGT GTC AGT ATG AAC and 18SR1 - CAT TCC AAT TAC AGG GTC TCG, and 28SF1 - GTC TTG AAA CAC GGA CCA AGG AGT and 28SR1 - CCC CGA GAC CTC TAA TCA TTC, as described by Bolek et al. (2010). Obtained PCR-products were directly sequenced in the commercial sequencing centre with the same primers.

Sequence alignments were generated using Clustal $\mathrm{X}$ under default values for gap opening and gap extension penalties. All alignments were analyzed using PAUP* 4.0b10 (Swof 

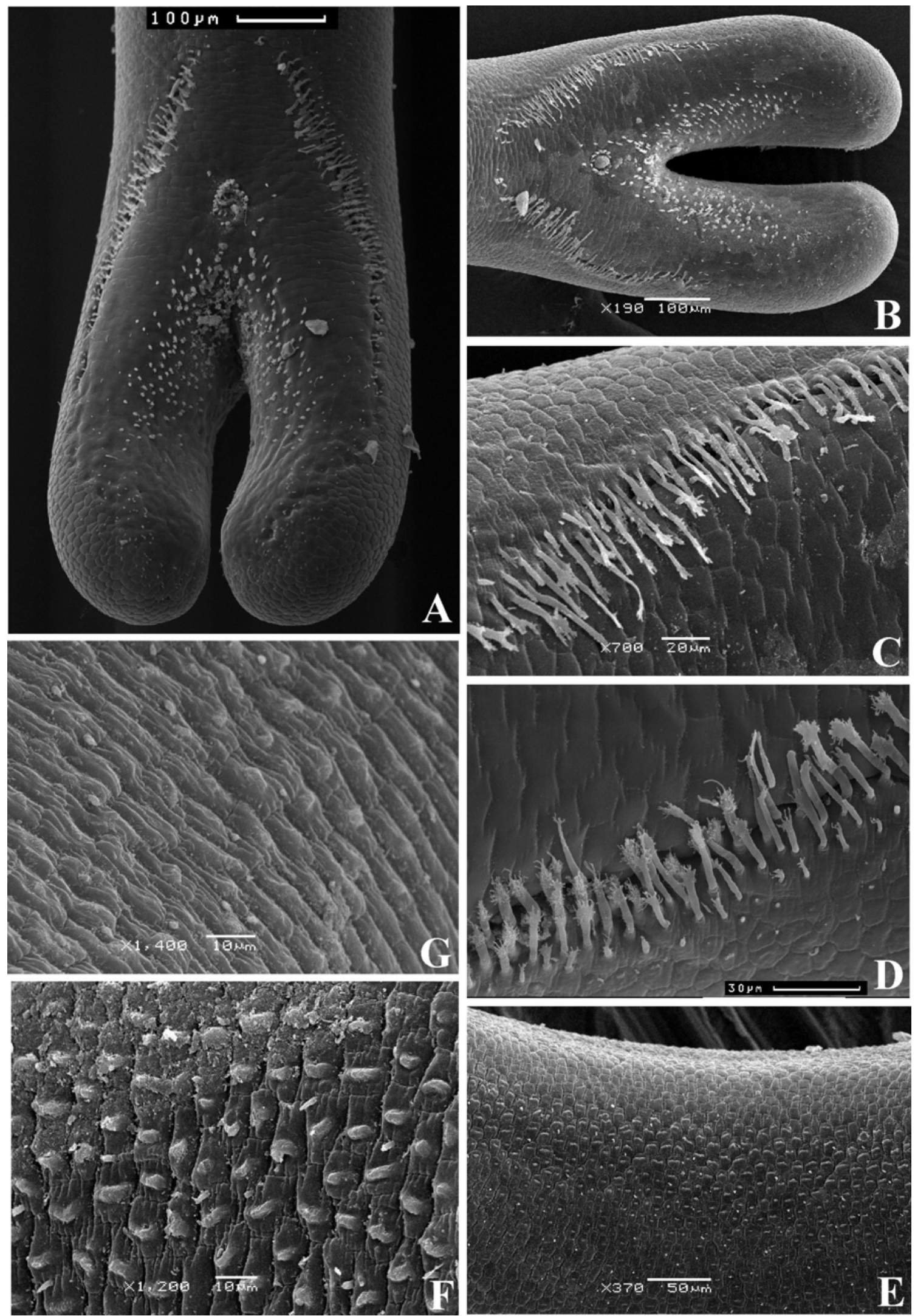

Fig. 1. Cuticular structures of Gordionus alpestris male from the North-West Caucasus. A, B - male tail, ventral view - two different specimens; C, D - field of adhesive warts, ; F - adhesive warts (closer to cloaca); G - adhesive warts (closer to lateral side in about $800 \mu \mathrm{m}$ before cloaca) 
ford 1998) for maximum parsimony (MP), distance method (NJ) and maximum likelihood (ML). The model for ML-analysis was selected with ModelTest 5.0. The accession numbers for the sequences originating from NCBI GenBank and used in this study are indicated on the phylograms.

\section{Results and discussion}

Gordionus alpestris (Villot, 1885) Figs. $1-3$.

Male specimens: $\mathrm{L}=191(340) \mathrm{mm} ; \mathrm{W}=0.03(0.06) \mathrm{g}$, $\mathrm{MBD}=0.36(0.29) \mathrm{mm}$.

Female specimens: $\mathrm{L}=545(506,392) \mathrm{mm} ; \mathrm{W}=0.13$ $(0.12 ; 0.04) \mathrm{g} ; \mathrm{MBD}=0.52(0.56 ; 0.47) \mathrm{mm}$.
Description. White or slightly yellowish worms. It seems that where worms were fixed immediately after emerging from a host the darker coloration did not develop. Cuticle surface in both sexes is with a single type of areoles hexagonal, rarely pentagonal areas of surface (Fig. 2 A, B, D). In males, interareolar furrows are slightly wider, areoles have sharper corners and walls of interareolar furrows have an undulating surface (Fig. 2 C, E). In females, areolar corners are more rounded, and undulating walls of the interareolar furrows are hardly conspicuous (Fig. 2 F). Very few short, rounded spines with the diameter of basal part about $0.7-0.85 \mu \mathrm{m}$ are scattered over the cuticle surface. The spines are squeezed between two neighbouring areoles. Usually, one areole from each pair is pentagonal, not hexagonal (Fig. 2 E, F).
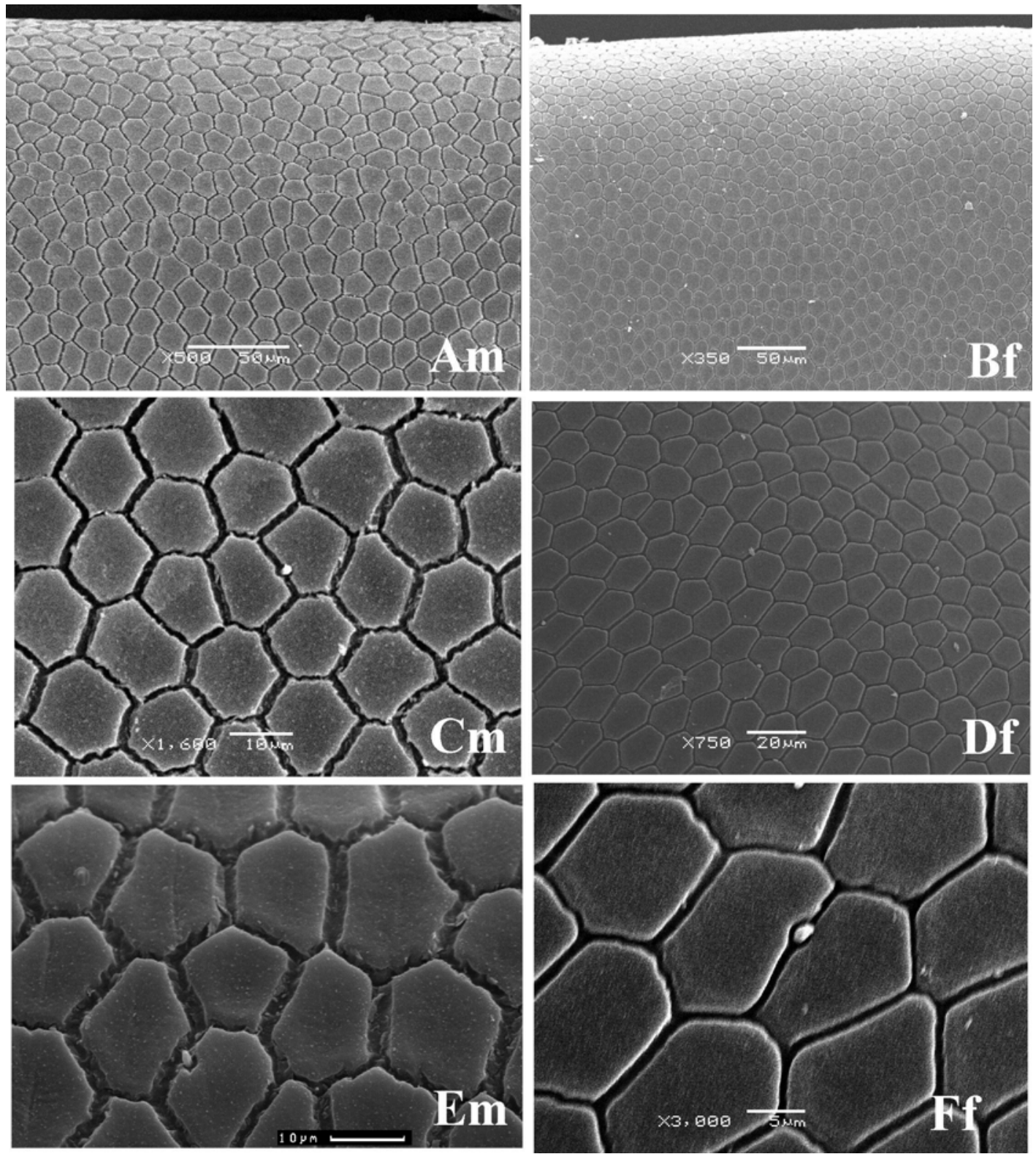

Fig. 2. Cuticular structures of Gordionus alpestris from the North-West Caucasus. A, C, E - male; B, D, F - female, A, B - general view of mid-body cuticle surface; C, D - polygonal shape of areoles; E, F - interareolar furrows and structures 


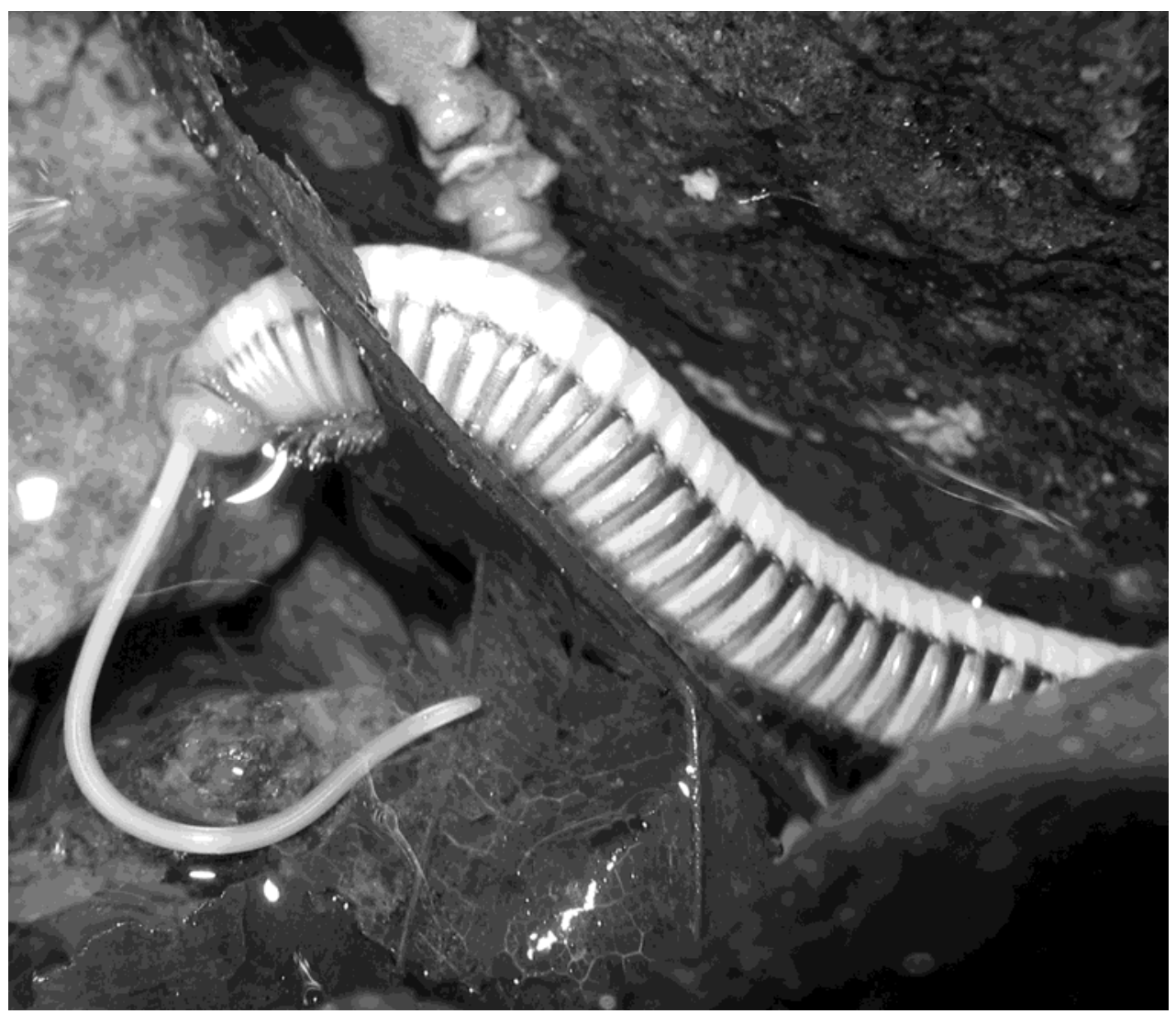

Fig. 3. Gordionus alpestris emerging from the tail segment of Pachyiulus krivolutskyi Golovatch, 1977 (Julidae, Diplopoda)

The posterior end of male has two slightly curved tail lobes (Fig. 1 A, B). Numerous spines of $2-6 \mu \mathrm{m}$ length are scattered over the ventral surface of the male posterior end. Precloacal bristlefields consist of about 50 bristles of variable length, with the longest ones in the middle of the field. Precloacal bristelfields extend anteriorly but do not fuse in the medioventral line, leaving a gap free of bristles anterior of the cloacal opening. The distal parts of the bristles are branching into numerous tiny spikes and hairs (Fig. $1 \mathrm{C}$, D). The base of the bristles is positioned in the center of an areole. Shorter bristles and spikes are visible on the lateral side of the fields. Two areas with adhesive warts are visible on the sublateral sides of the male posterior end (Fig. 1 E). Adhesive warts are quite rounded, ridge-like (not flattened) and only modestly elongated along the longitudinal body axis. The size of adhesive warts decreases toward lateral sides (Fig. $1 \mathrm{G}$ ). The shape of the cloacal opening varies from circular to elliptical. Margins of the cloacal opening bear $20-25$ circumcloacal spines with rounded tips.

Host. Diplopods Pachyiulus krivolutskyi Golovatch, 1977. Locality of collection: Diplopods and nematomorphs were collected in the deciduous woodland (Fagus sylvatica + Carpinus betulus) along the Zolotoi stream, left tributary of the river Belaya (which itself is the left tributary of Kuban river). Nematomoprhs emerged from a host body usually by piercing intersegmental membranes in the tail from beneath the anal valves of a diplopod (Fig. 3). The collection site is located $2.5 \mathrm{~km}$ from the biological station of the Southern Federal University (Rostov-na-Donu). Approximate coordinates are $44^{\circ} 9^{\prime} 46.13^{\prime \prime N ~ 40^{\circ}} 7^{\prime} 56.89^{\prime \prime} \mathrm{E}$. Date of collection: June 11, 2009.

Taxonomic remarks. The described specimens of Gordionus from the North-West Caucasus showed the following set of morphological features: areoles polygonal with round corners, adhesive warts in the shape of short ridges, circumcloacal spines present, precloacal bristelfields not fused anterior to the cloacal opening, postcloacal spines situated separately, but not in groups, very few interareolar structures, bristles in fields mainly branched. According to the 'Key to the species of Gordionus' (Schmidt-Rhaesa, 1997), these are identified as Gordionus alpestris (Villot, 1885). This nematomorph species is widely distributed in Europe. Diplopod hosts of $G$. alpestris were mentioned by Dorier (1929): Julus sp. and by Căpuşe (1971): Polydesmus complanatus. North American spirostreptid diplopod Cambala annulata was reported as host for Nearctic Gordionus lineatus in Ohio, USA by A. Schmidt-Rhaesa and his co-authors (2009), who also proposed a review of all reports of myriapods as hosts of nematomorphs. It was also mentioned that Gordionis alpestris, Gordius aquaticus, and Gordius villoti are the only nematomorph parasites of diplopods identified up to the species level. 

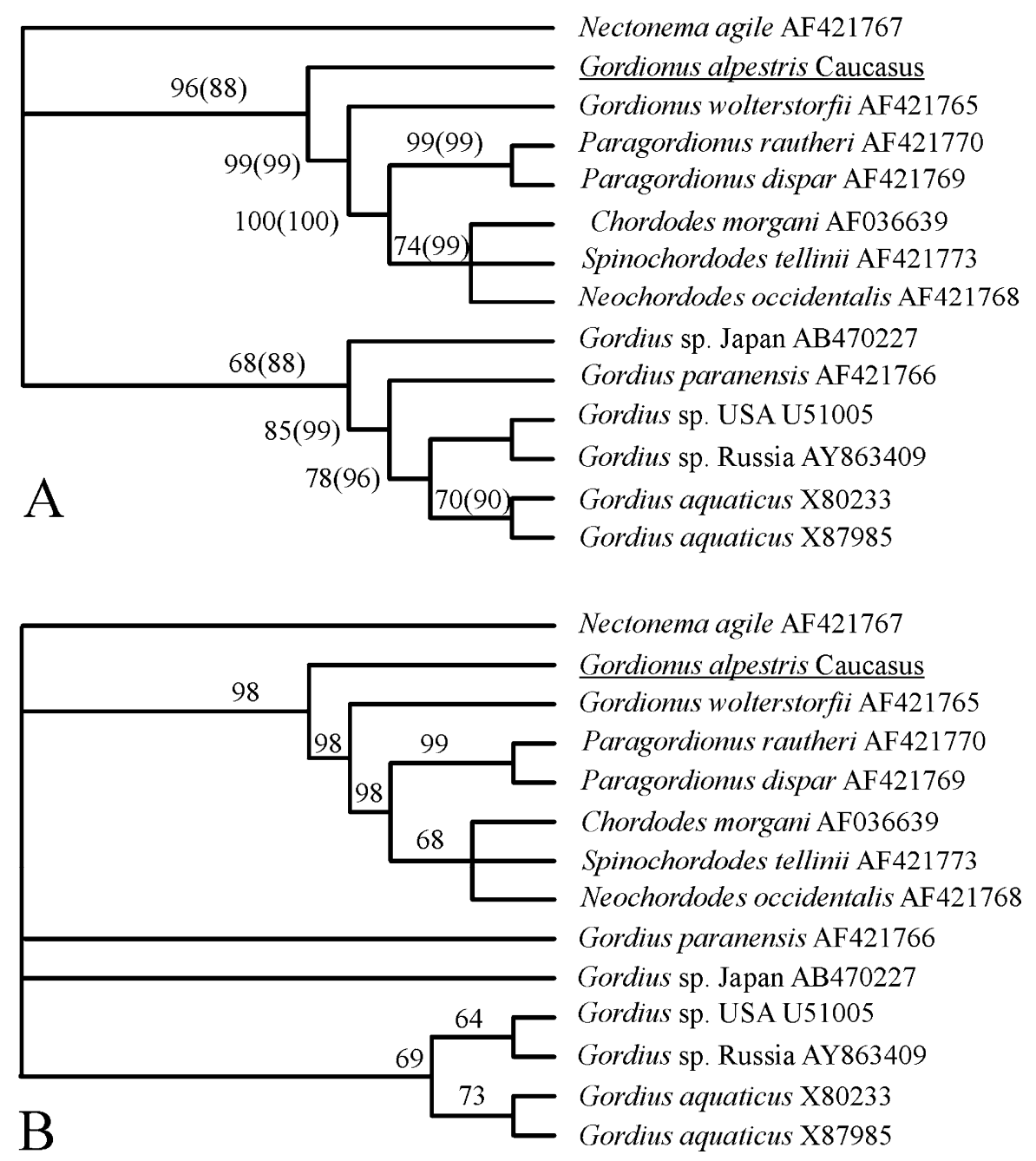

Nectonema agile AF421767

Gordionus alpestris Caucasus

Gordionus wolterstorfii AF421765

Paragordionus rautheri AF421770

Paragordionus dispar AF421769

Chordodes morgani AF036639

Spinochordodes tellinii AF421773

Neochordodes occidentalis AF421768

Gordius paranensis AF421766

Gordius sp. Japan AB470227

Gordius sp. USA U51005

Gordius sp. Russia AY863409

Gordius aquaticus X80233

Gordius aquaticus X87985

Fig. 4. Phylogenetic relationships between Gordionus alpestris from the North-West Caucasus and other nematomorphs. A - Maximum parsimony and Neighbour Joining analysis. Of 895 total characters: 693 characters are constant. Number of parsimony-informative characters $=60$; 10000 bootstrap repeats; bootstrap values presented near the nodes in the format MP(NJ). B - Maximum likelihood analysis. $\mathrm{TrN}+\mathrm{I}+\mathrm{G}$ model selected. $-\operatorname{lnL}=2453.7349,100$ bootstrap repeats; bootstrap values near the nodes

Molecular characterization. Three repetitive sequencing reactions of both $18 \mathrm{~S}$ and $28 \mathrm{~S}$ rDNA PCR-products were ordered. The $883 \mathrm{bp}$ long $18 \mathrm{~S}$ sequence and $393 \mathrm{bp}$ long 28S rDNA sequences were obtained and deposited in GenBank as JN129261 and JN208924 correspondingly. Totally thirteen $18 \mathrm{~S}$ sequences were available for the comparison of G. alpestris sequences with other nematomorphs. According to the analysis of $18 \mathrm{~S}$ rDNA, G. alpestris from North-West Caucasus did not show any affiliation with the sequence of the only other studied representative of the genus Gordionus - G. wolterstorffii (AF421765), which is connected to the basal node for all Chordodidae (Fig. 4). Such a pattern was obvious under all implemented methods of analysis (MP, NJ and ML). Only three 28S rDNA sequences were available, and again the sequence obtained for G. alpestris from NorthWest Caucasus was quite aberrant with $26-31$ bp difference compared to representatives of the genera Gordius and Chordodes. The differences between Gordius and Chordodes were on the level of $5-7 \mathrm{bp}$ only in the sequence of about 400 bp.

An unexpectedly high level of differences was observed in $18 \mathrm{~S}$ and $28 \mathrm{~S}$ sequences between Gordionus alpestris found in diplopods in North-West Caucasus and other molecularly studied representatives of the family Chordodidae. As direct sequencing was used and obtained sequences corresponded in all three repeated sequence reactions, we think that sequencing errors are quite unlikely. Some features (e.g. adhesive warts) of the Gordionus morphology were only reported for some, but not all species of the genus. Thus, we still can not exclude that this genus is representing an artificial paraphyletic grouping of nematomorphs (Schmidt-Rhaesa, 2002). Wider studies of the rDNA sequences of the chordodid nematomorphs are needed to elucidate this controversy. It is also reasonable to presume that more domains of nuclear and mitochondrial DNA are to be involved into the molecular characterization of nematomorphs thus increasing the reliability of phylogenetic analysis. 


\section{Acknowledgement}

The authors are grateful to Dr Andreas Schmidt-Rhaesa (Biocentre Grindel and Zoological Museum, University Hamburg) for his help during preparation of the paper. The expenses on the sequencing were covered from the programme 'Bioresources' of the Russian Academy of Sciences.

\section{References}

BoleK, M. G., Schmidt-Rhaesa A., Hanelt, B., \& RICHARDSON. J. (2010): Redescription of the African Chordodes albibarbatus Montgomery 1898, and description of Chordodes janovyi n. sp. (Gordiida, Nematomorpha) and its non-adult stages from Cameroon, Africa. Zootaxa, 2631: 36 - 54

CĂPUŞE, I. (1971): Nouvelles données sur la répartition et la biologie de quelques Gordiides de Roumanie. Travaux du Museum National d'Histoire Naturelle "Grigore Antipa" 10: 49 - 56

DORIER, A. (1929): Sur les Gordiacés des Myriapods. Comptes Rendus de l'Académie des Sciences, Paris, 188: $743-745$

SchmidT-RhaesA, A. (1997): Nematomorpha. In: Süsswasserfauna von Mitteleuropa. Band 4/4. Stuttgart, BRD, G.Fisher Verlag, 128 p.

SCHMIDT-RHAESA, A. (2002): Are the genera of Nematomoprha monophyletic taxa? Zoologica Scripta 31, N 2, pp. $185-200$

SCHMIDT-RhaESA, A., FARfan M. A., BERnARD, E.C. (2009). First Record of Millipeds as Hosts for Horsehair Worms (Nematomorpha) in North America. Northeastern Naturalist, 16(1): 125 - 130

SWOFFORD, D. L. (1998): PAUP* - Phylogenetic analysis using parsimony (and other methods). Version 4.0b10 [computer software]. Sunderland, Massachusetts, Sinauer Associates. 